\title{
LẬP BẢN ĐỒ DỬ BÁO SỬ DỤNG ĐẤT TỈNH BÌNH DƯƠNG ĐẾN NĂM 2030 BẰNG MÔ HÌNH LAND CHANGER MODELER (LCM) KẾT HỢP DŨ' LIỆU ẢNH VỆ TINH LANDSAT
}

\author{
ĐÕ TH!̣ PHƯO'NG THẢO(1), MAI VĂN SỸ (2), \\ BÙI NGOC QUÝ( ${ }^{(1)}$, NGHIÊM TH! HUYĖN ${ }^{(1)}$ \\ (1)Trường đại học Mỏ - Địa chất \\ ${ }^{(2)}$ Công ty Cổ phần tư vấn thiết kế Công trình Xây dựng Hải Phòng
}

\section{Tóm tắt:}

Mục đích của nghiên cứu này là thành lập bản đồ dụ báo biến động sử dụng đất giai đoạn trung hạn và dài hạn của tỉnh Bình Dương với nhiều lớp đối tượng sử dụng đất bằng mô hình dự báo LCM và dữ liệu ảnh vệ tinh Landsat. Kết quả phân tích bản đồ dự báo đến năm 2030 cho thấy một số loại hình sử dụng đất sẽ thay đổi đáng kể có thể gây ra mối đe dọa nghiêm trọng đến môi trường đô thị và ảnh hưởng đến việc phát triển bền vững của khu vực.

\section{1. Đặt vấn đề}

Việt Nam là một trong những quốc gia dễ bị ảnh hưởng nhất bởi biến đổi khí hậu: nhiệt độ trung bình tăng $0,26^{\circ} \mathrm{C}$ mỗi thập kỷ và đã cao gấp đôi so với tốc độ tăng bình quân trên toàn cầu; biến thiên lượng mưa giữa các mùa dự báo là cũng sẽ tăng, mùa mưa sẽ mưa nhiều hơn và mùa khô sẽ khô hơn. Nếu xu thế này cứ tiếp diễn, các loại hình sử dụng đất dự kiến sẽ bị ảnh hưởng mạnh, trong đó khu vực miền Đông Nam Bộ cũng sẽ chịu rủi ro lớn hơn không những từ tác động trực tiếp do biến đổi khí hậu mà còn vì đây là khu vực có tốc độ phát triển thuộc tốp đầu của cả nước (Việt Nam 2035). Hiện nay, xu hướng sử dụng các mô hình để xây dựng các kịch bản tài nguyên môi trường đang ngày càng phổ biến, các kịch bản này là công cụ không thể thiếu trong việc xây dựng hệ thống hỗ trợ ra quyết định phục vụ công tác quản lý và quy hoạch lãnh thổ. Tuy nhiên, trong khi các kịch bản (dự báo) tài nguyên nước, kịch bản sự cố vỡ hồ, đập cấp quốc gia, cấp vùng đã được triển khai xây dựng thì các kịch bản biến động sử dụng đất vẫn chưa có một luận cứ vững chắc để đưa ra trên bình diện cấp vùng hoặc cấp quốc gia. Trên thế giới, có rất nhiều các kiểu mô hình được sử dụng để dự báo biến động sử dụng đất, chẳng hạn như mô hình toán học, mô hình thống kê, mô hình phân tích xu hướng (hệ thống đa tác nhân), mô hình tế bào (cellular automata) và các mô hình dựa trên một phương pháp gọi là gần đúng [7], [9] nhưng các mô hình như chuỗi Markov, CA-Markov, GEOMOD và LCM mới là những mô hình cho thấy được sự hiệu quả trong việc dự đoán biến động sử dụng đất vì chúng được kết hợp với hệ thống thông tin địa lý (GIS), dữ liệu vệ tinh viễn thám trong phân tích dữ liệu, mô phỏng các xác suất của sự thay đổi và nâng cao độ tin cậy kết quả dự đoán sử dụng đất trong tương lai [4].

\section{Khu vực nghiên cứu}

Bình Dương là một tỉnh thuộc miền Đông Nam Bộ, nằm trong vùng kinh tế trọng điểm phía Nam; là một trong những tỉnh có tốc độ tăng trưởng kinh tế cao, phát triển công nghiệp năng động của cả nước; diện tích tự nhiên là $2.695 .22 \mathrm{~km}^{2}$, với địa hình khu vực tương đối bằng phẳng, hệ thống sông ngòi

Ngày nhận bài: 20/02/2017, ngày chuyển phản biện: 21/02/2017, ngày chấp nhận phản biện: 05/03/2017, ngày chấp nhận đăng: 06/3/2017 
và tài nguyên thiên nhiên phong phú (hình 1). Khí hậu mang đặc điểm nhiệt đới gió mùa, nóng ẩm với 2 mùa rõ rệt: mùa mưa từ tháng 5-11, mùa khô từ khoảng tháng 12 năm trước đến tháng 4 năm sau, lượng mưa trung bình hàng năm từ $1800 \mathrm{~mm}$ $2000 \mathrm{~mm}$. Nhiệt độ trung bình hằng năm là $26,5^{\circ} \mathrm{C}$. Dân số của tỉnh là 1.482 .636 người (1/4/2009), mật độ dân số khoảng 550 người $/ \mathrm{km}^{2}$, gồm 7 đơn vị hành chính trực thuộc trong đó Thủ Dầu Một là trung tâm kinh tế - chính trị - văn hóa của tỉnh. Trong những năm gần đây, tốc độ tăng trưởng kinh tế luôn ở mức cao, GDP tăng bình quân khoảng 14,5\%/năm. Cơ cấu kinh tế chuyển biến tích cực, công nghiệp, dịch vụ tăng trưởng nhanh và chiếm tỷ trọng cao điển hình năm 2010, tỷ lệ công nghiệp - xây dựng là $63 \%$, dịch vụ $32,6 \%$ và nông lâm nghiệp 4,4\%.

\section{Dữ liệu và phương pháp}

\subsection{Chuẩn bị dữ liệu}

\subsubsection{Dữ liệu viễn thám}

Dữ liệu ảnh vệ tinh Landsat được lựa chọn trong nghiên cứu này bao gồm Landsat5TM (2000), Landsat7 ETM+ (2009) và Landsat8 OLI_TIR (2015) để thành lập các bản đồ sử dụng đất các năm tương ứng. Ngoài ra, dữ liệu Spot, Quickbird có độ phân giải cao $(2,5 \mathrm{~m})$ và siêu cao $(0,6 \mathrm{~m})$ cũng được sử dụng như là tài liệu hố trợ trong quá trình chọn mẫu phân loại sử dụng đất và trong quá trình kiểm tra kết quả sau phân loại.

\subsubsection{Bản đồ địa hình}

Bản đồ địa hình tỉ lệ 1:50.000 (được hiện chỉnh năm 2011) được sử dụng làm tài liệu hỗ trợ trong quá trình xác định các mẫu giải đoán ảnh; xác định vị trí các điểm khảo sát thực địa trong quá trình thu thập dữ liệu; xây dựng cơ sở dữ liệu đường giao thông, mạng lưới thủy hệ phục vụ chạy mô hình LCM.

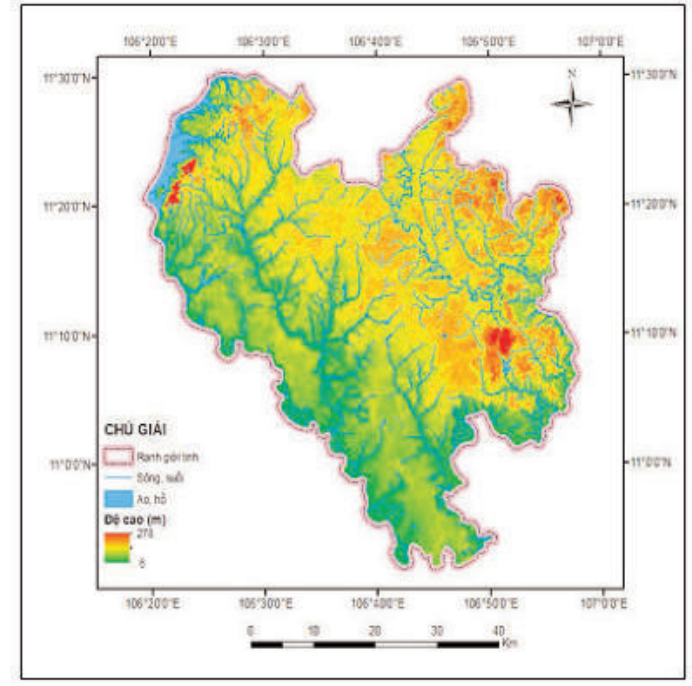

\subsubsection{Dũ liệu thực địa}

Dũ liệu thực địa thu thập vào tháng 4 năm 2015 được sử dụng để kiểm tra độ chính xác bản đồ sử dụng đất sau phân loại; để xác định các lớp sử dụng đất khác nhau và vị trí chính xác của điểm khảo sát thực địa. Sử dụng máy ảnh kỹ thuật số, bản đồ địa hình và ảnh vệ tinh của khu vực nghiên cứu (được in trên giấy ảnh), ảnh khảo sát thực địa của mỗi loại hình sử dụng đất để chụp tại nhiều địa điểm khác nhau nhằm đảm bảo tính chính xác của các dữ liệu thu thập được.

\subsection{Mô đun Land Change Modeler (LCM)}

Land Change Modeler (LCM) là một môđun tổng hợp được sử dụng cho việc phân tích, dự báo các thay đổi sử dụng đất, đánh giá các yếu tố ảnh hưởng đến đa dạng sinh học và quy hoạch lãnh thổ [1], [2]. Việc mô hình hóa biến động sử dụng đất sử dụng mô đun LCM đòi hỏi phải có hai bản đồ hiện trạng sử dụng đất tương ứng với hai thời điểm khác nhau $\mathrm{T} 1$ và $\mathrm{T} 2$; các bản đồ này được sử dụng như là dữ liệu đầu vào để phân tích các thay đổi sử dụng đất trong quá khứ, giúp cho việc nắm bắt các thông tin về sự tăng, giảm và các vùng chuyển đổi của các loại sử dụng đất khác nhau[6]. Mô 
đun này cũng định lượng được những thay đổi sử dụng đất trong giai đoạn $\mathrm{T} 1$ và $\mathrm{T} 2$ [5],[6]. Mô đun LCM cho phép dự báo sự biến động sử dụng đất với một, hai hoặc nhiều lớp sử dụng đất cùng một lúc trên cơ sở của quá trình chuyển đổi tiềm năng (khả năng chuyển đổi), mối quá trình chuyển đổi được mô hình hóa bằng một hàm hồi quy logistic hoặc mạng thần kinh đa lớp [1],[3]. Nếu lựa chọn thuật toán thích hợp với mục tiêu đặt ra, các bản đồ dự báo biến động sử dụng đất có thể có độ chính xác cao hơn $70 \%$ [10] và cho phép trực tiếp xuất ra bản đồ dự báo sử dụng đất với các tên và số lượng lớp như các bản đồ hiện trạng đầu vào.

Quy trình lập bản đồ dự báo biến động sử dụng đất dựa trên mô hình LCM được tóm tắt ở sơ đồ hình 2 , theo quy trình, trước tiên quá trình biến động sử dụng đất được xác định dựa trên việc phân tích đa thời gian của các bản đồ hiện trạng sử dụng đất; tiếp theo, các yếu tố thực sự có ảnh hưởng (các biến giải thích) đến sự biến động trên được đánh giá và xác định. Lịch sử biến động sử dụng đất và các nguồn thông tin mô tả các biến giải thích được tích hợp vào mô hình LCM để xây dựng các kịch bản sử dụng đất với thuật toán hồi quy logistic (Logistic Regression, viết tắt là LogReg) hoặc mạng thần kinh đa lớp (Multi-Layer Perceptron, viết tắt là $\mathrm{PMC}$ ) sau đó áp dụng chuỗi Markov để lập bản đồ dự báo sử dụng đất ở một thời điểm hiện tại nhằm hiệu chỉnh mô hình; kế tiếp là tiến hành đánh giá kết quả hiệu chỉnh mô hình bằng cách so sánh bản đồ dự báo sử dụng đất với bản đồ tài liệu ở cùng thời điểm; cuối cùng là xây dựng các kịch bản sử dụng đất trong ngắn hạn, trung hạn và dài hạn. (Xem hình 2)

\section{Kết quả}

\subsection{Phân tích biến động sử dụng đất}

\subsubsection{Thành lập các bản đồ hiện trạng}

Các bản đồ hiện trạng sử dụng đất tỉnh

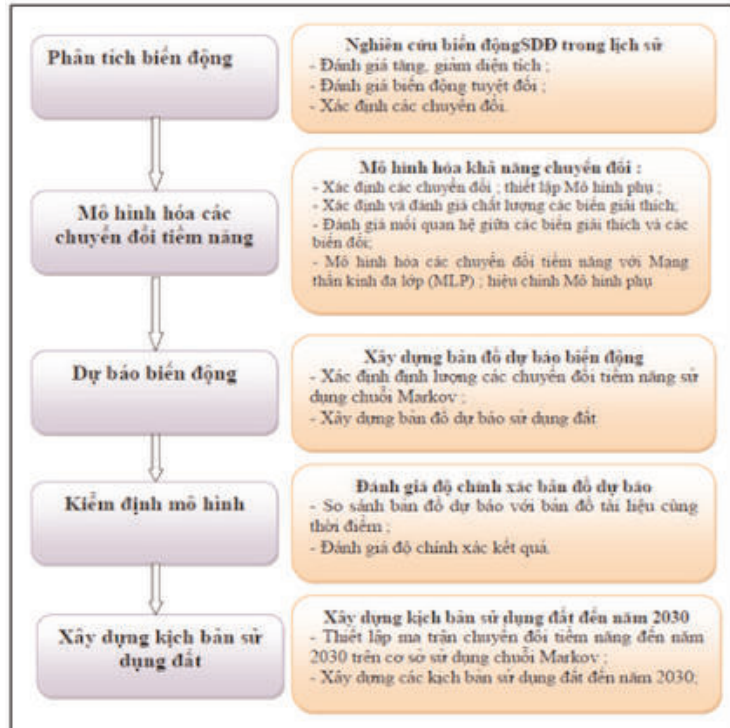

Hình 2: Dự báo biển động sự dụng đất bằng mô hình LCM

Bình Dương được xây dựng theo hướng tiếp cận lớp phủ, trên đó phải thể hiện được các loại hình sử dụng đất cơ bản đặc thù của tỉnh. Qua khảo sát thực địa và tham khảo các bản đồ hiện trạng đã có, 6 lớp đối tượng sử dụng đất được mô tả và lựa chọn như bảng 1.

Bản đồ sử dụng đất năm 2015 được xây dựng trước, sau đó đến bản đồ năm 2009 và cuối cùng là bản đồ năm 2000. Mẫu giải đoán ảnh các năm được xây dựng dựa trên dữ liệu khảo sát thực địa kết hợp giải đoán trên ảnh độ phân giải siêu cao (Quickbird). Các mẫu ảnh được phân bố rải đều trên toàn khu vực nghiên cứu, trên cơ sở đó tiến hành phân loại sử dụng đất theo thuật toán xác xuất cực đại là thuật toán được áp dụng rộng rãi ở Việt Nam và trên thế giới. Để đánh giá độ chính xác, kết quả phân loại sử dụng đất năm 2015 được so sánh với tài liệu khảo sát thực địa, trong khi tài liệu tham khảo cho các năm 2009 và 2000 được xây dựng từ các tài liệu bổ trợ như bản đồ địa hình, bản đồ hiện trạng sử dụng đất các năm 2000 và 2010 cấp tỉnh. Các chỉ số thống kê đánh giá độ chính xác kết quả phân loại sử dụng đất năm 2000, 2009 và 
2015 tỉnh Bình Dương cho thấy, độ chính xác chung kết quả phân loại nằm trong khoảng từ 86-91\%, lớn hơn giá trị yêu cầu (85\%). Tương tự, hệ số Kappa nằm trong khoảng từ 0,83 đến 0,9 đảm bảo so với yêu cầu là trên 0,8 . (Xem bảng 1 )

\subsubsection{Phân tích biến động sử dụng đất}

Biến động sử dụng đất trong giai đoạn 2000-2009 của tỉnh Bình Dương được phân tích thông qua mô hình LCM từ bản đồ sử dụng đất các năm tương ứng, thể hiện đồng thời sự tăng và giảm diện tích của từng lớp đối tượng. Kết quả cho thấy hầu hết các lớp đối tượng sử dụng đất đều có biến động: diện tích đất trồng cây công nghiệp, đất cây ăn quả và đất dân cư (cơ sở hạ tầng) tăng rõ rệt, giá trị tăng tương ứng 22000 ha, 18000 ha và 11000 ha trong giai đoạn 2000-2009, ngược lại, diện tích đất nông nghiệp và rừng giảm mạnh, tương ứng khoảng 36000 ha và 15000 ha. Sự suy giảm diện tích đất nông nghiệp và đất rừng có thể được giải thích là do sự chuyển đổi mục đích sử dụng đất sang trồng cây công nghiệp, cây ăn quả, xây dựng khu dân cư, cơ sở hạ tầng và các khu công nghiệp. Phân bố không gian biến động từng lớp đối tượng sử dụng đất của tỉnh Bình Dương giai đoạn 2000-2009 cho thấy khu vực có màu đỏ đậm là những khu vực có sự biến động mạnh, khu vực có màu xanh nhạt là những khu vực không có biến động hoặc những khu vực ít có sự biến động còn khu vực có màu xanh đậm, trên thang phân tầng màu có giá trị âm, là những khu vực không có dữ liệu. (Xem hình 3)

Hình $3 a$ cho thấy sự biến động diện tích đất trồng cây ăn quả diễn ra mạnh mẽ ở khu vực giữa của tỉnh, đây cũng là khu vực được xem như có sự phát triển mạnh mẽ vùng chuyên canh cây ăn quả, trong khi đó, sự biến động đối với nhóm đất trồng cây công nghiệp (hình $3 b$ ) diễn ra chủ yếu ở khu vực phía Đông Bắc của tỉnh, sự biến động ở đây chủ yếu là sự chuyển đổi từ đất rừng sang đất trồng cây lâu năm như cà phê, cao su. Hình $3 c$ thể hiện không gian biến động của đất dân cư diễn ra trên toàn tỉnh và tập trung chủ yếu ở khu vực phía đông nam, chính là khu vực thành phố Thủ Dầu Một, nơ có tốc độ phát triển kinh tế và đô thị hóa mạnh mẽ trong vòng 20 năm qua. Sự phát triển của khu vực này đi kèm với sự chuyển đổi từ đất hoa màu, đất lúa nước sang đất thổ cư, đất khu công nghiệp và cơ sở hạ tầng giao thông.

\subsection{Mô hình hóa các chuyển đổi tiềm năng}

Mô hình hóa các chuyển đổi tiềm năng (hay còn được gọi là các khả năng chuyển đổi) là một bước quan trọng nhằm xây dựng các biến giải thích (các chuyển đổi đã xảy ra thông qua phân tích biến động sử dụng đất

\section{Bảng 1: Bảng phân loại sử dụng đất tỉnh Bình Dương}

\begin{tabular}{|c|c|r|}
\hline STT & Lớp đối tượng & Mô tả \\
\hline 1 & Đất rừng & Là rừng tự nhiên có độ che phủ tán từ 20-70\% \\
\hline 2 & Đất nông nghiệp & $\begin{array}{r}\text { Là vùng đất trồng lúa nước, lúa nước xen hoa màu, đất trồng cây } \\
\text { hàng năm như ngô, khoai, sắn, lạc }\end{array}$ \\
\hline 3 & Cây công nghiệp & Đất trồng cây công nghiệp lâu năm như cao su, cà phê \\
\hline 4 & Cây ăn quả & Đất trồng cây ăn quả lâu năm như: cam, bưởi, sầu riêng, xoài \\
\hline 5 & Đất dân cư & Gồm đất ở, đất khu công nghiệp, đất giao thông \\
\hline 6 & Mặt nước & Đất sông, hồ, ao nuôi trồng thủy sản, đất ngập nước \\
\hline
\end{tabular}


trong quá khứ), đưa vào thiết lập mô hình chuyển đổi phụ (là mô hình phân tích, đánh giá khả năng chuyển đổi của từng lớp đối tượng sử dụng đất) để tính toán và xác định khả năng chuyển đổi các đối tượng sử dụng đất trong tương lai. Kết quả phân tích đã xác định được danh mục các biến động sử dụng đất giai đoạn 2000 - 2009 của tỉnh Bình Dương, trong đó đất cây ăn quả, đất nông nghiệp, đất rừng lần lượt được chuyển sang 4 loại hình sử dụng đất khác và đất mặt nước chuyển sang 2 loại hình sử dụng đất khác.

Sự biến động sử dụng đất còn bị tác động bởi nhiều yếu tố, trong đó có các yếu tố tự nhiên như địa hình (độ dốc, hình thái, hướng sườn), hệ thủy văn, thổ nhưỡng, nhiệt độ, lượng mưa,... có cả những yếu tố do con người gây ra như giao thông, dân cư, đô thị hóa,... Mỗi một yếu tố trên được coi là một biến giải thích khi đưa vào mô hình chuyển đổi phụ, 9 biến giải thích đặc trưng được áp dụng trong xây dựng bản đồ dự báo sử dụng đất, được thống kê trong bảng 2. Trong bảng 2, các yếu tố Thủy văn, Giao thông, Điểm dân cư được đưa vào mô hình dưới dạng bản đồ chỉ số khoảng cách đến các đối tượng này. Các biến giải thích này được xây dựng dựa trên tính toán khoảng cách Ơclit (Euclidean) đo được giữa pixel đến điểm mục tiêu gần nhất. Việc tính toán khoảng cách này được thực hiện trên phần mềm IDRISI, với đầu vào là bản đồ mạng lưới thủy văn, giao thông, điểm dân cư và đầu ra là các bản đồ khoảng đến thủy văn, đến giao thông, đến điểm dân cư. (Xem bảng 2)

Các tham số trong bảng trên có mức độ và vai trò ảnh hưởng đến sự biến động sử dụng đất là khác nhau, do đó các biến giải thích trong mô hình chuyển đổi phụ có trọng số khác nhau được đánh giá thông qua chỉ số Cramer's V, (tiêu chuẩn đổi với các biến giải thích). Giá trị chỉ số Cramer's $\mathrm{V}$ cao được coi như có mối liên kết chặt chẽ đến biến động sử dụng đất. Về mặt lý thuyết, chỉ

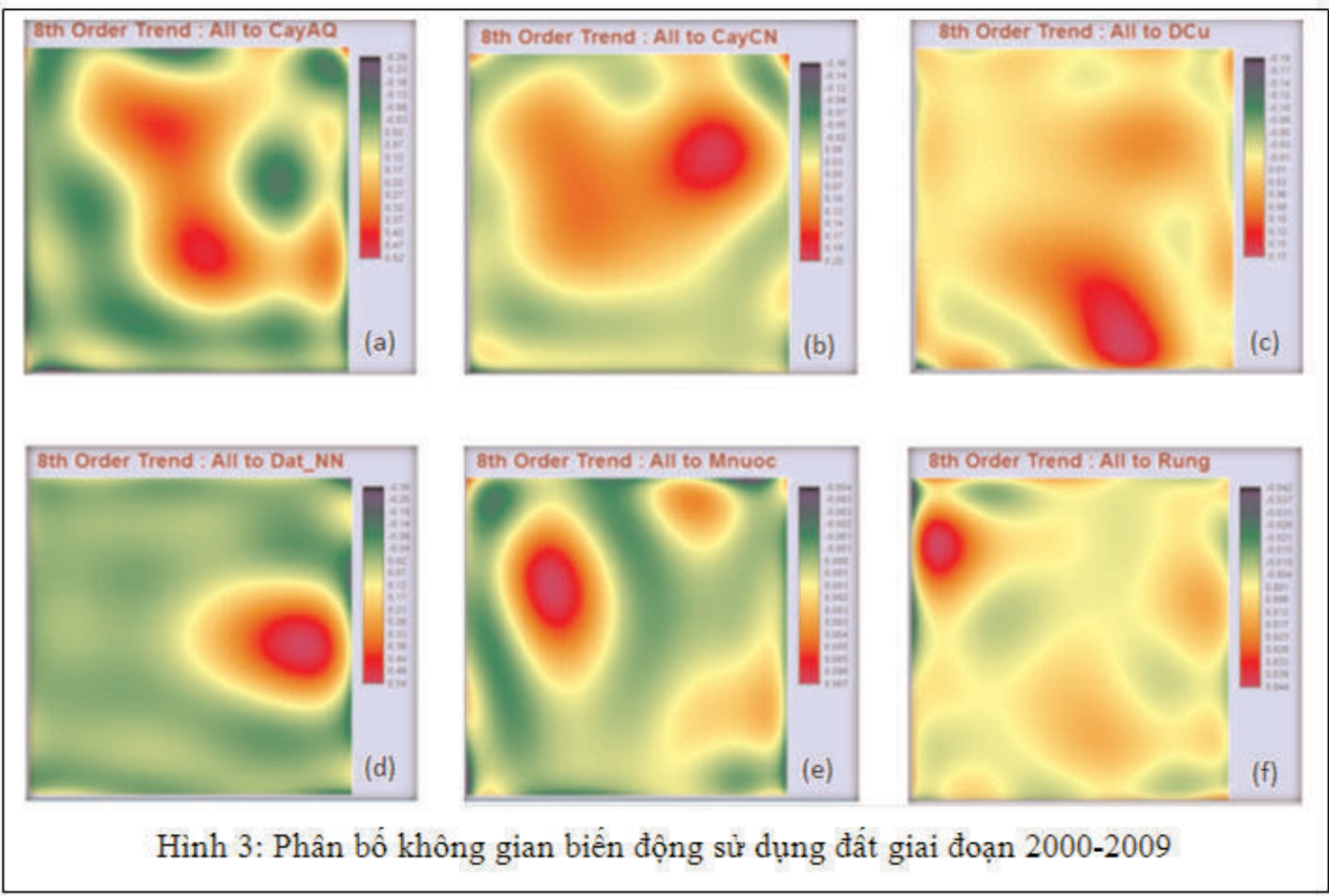


số Cramer's $\mathrm{V}$ lớn hơn hoặc bằng 0,15 được coi là chấp nhận được; nằm trong khoảng 0,4 khi đó các biến giải thích được coi là rất có ảnh hưởng đến quá trình mô hình quá biến động sử dụng đất [2]. Trong nghiên cứu này các giá trị Cramer's $\mathrm{V}$ của từng biến giải thích đều lớn hơn 0.15 chứng tỏ rằng tất cả các yếu tố đều có mối quan hệ khăng khít đến biến động sử dụng đất trong khu vực, do vậy cả 9 biến giải thích trên đều đưa vào chạy mô hình chuyển đổi phụ sử dụng mạng thần kinh đa lớp, phục vụ việc xây dựng bản đồ dự báo sử dụng đất đến năm 2030. Quá trình chạy mô hình phụ, các tham số của mô hình (số lượng mẫu, số lượng biến, giá trị tính toán ban đầu,...) được hiệu chỉnh sao cho độ chính xác tính toán bản thân của mô hình đạt ít nhất $75 \%$. Các số liệu thống kê đánh giá độ chính xác hiệu chỉnh mô hình phụ cho thấy, giá trị sai số trung phương (RMS) chọn mấu tính toán của mô hình là khá nhỏ (giá trị này trước khi hiệu chỉnh là 0.48 đã giảm xuống còn 0.1445 sau khi hiệu chỉnh). Độ chính xác của mô hình chuyển đổi phụ đạt $76.63 \%$, cao hơn giá trị tiêu chuẩn yêu cầu $(75 \%)$, khi mô hình chuyển đổi phụ tính đến lần lặp thứ 7000 trở đi.

\subsection{Thành lập bản đồ dụ̣ báo sử dụng đất}

Trước tiên cần xây dựng bản đồ dự báo sử dụng đất đến thời điểm hiện tại (2015) để so sánh với bản đồ sử dụng đất năm 2015 đã thành lập từ ảnh Landsat8 OLI_TIRS (được coi là tài liệu tham khảo có độ chính xác tốt, đã được kiểm chứng) nhằm đánh giá độ chính xác của mô hình LCM. Quá trình này được thực hiện thông qua đánh giá độ chính xác từng lớp đối tượng sử dụng đất, hệ số Kappa và độ chính xác chung của bản đồ dự báo sử dụng dất. Kết

Bảng 2: Các biến giải thích áp dụng trong mô hình chuyển đổi phụ

\begin{tabular}{|c|c|c|c|}
\hline STT & Tên yếu tố & Mô tả & Tên biến giải thích \\
\hline 1 & Thủy văn & $\begin{array}{c}\text { Hệ thống thủy văn bao gồm sông, suối, } \\
\text { hồ }\end{array}$ & Khoảng cách đến hệ thủy văn \\
\hline 2 & Đường giao thông & Hệ thống giao thông chính & Khoảng cách đến giao thông \\
\hline 3 & Điểm dân cư & $\begin{array}{l}\text { Các điểm dân cư chính như thị trấn, thị } \\
\text { xã, thành phố }\end{array}$ & Khoảng cách đến điểm dân cư \\
\hline 4 & Địa hình & $\begin{array}{l}\text { Yếu tố địa hình bề mặt được thể hiện } \\
\text { dưới dạng mô hình số địa hình (DEM) }\end{array}$ & DEM \\
\hline 5 & Độ dốc & $\begin{array}{l}\text { Yếu tố địa hình bề mặt được thể hiện } \\
\text { dưới dạng độ dốc }\end{array}$ & Độ dốc (\%) \\
\hline 6 & Hình thái bề mặt & $\begin{array}{c}\text { Yếu tố địa hình bề mặt được thể hiện } \\
\text { dưới dạng hình thái bề mặt, hướng } \\
\text { sườn }\end{array}$ & Aspect \\
\hline 7 & Lương mưa & $\begin{array}{l}\text { Yếu tố khí hậu thể hiện theo phân bố } \\
\text { lượng mưa trung bình năm }\end{array}$ & Lượng mưa \\
\hline 8 & Nhiệt độ & $\begin{array}{l}\text { Yếu tố khí hậu thể hiện theo nhiệt độ } \\
\text { trung bình năm }\end{array}$ & Nhiệt độ \\
\hline 9 & Thổ nhưỡng & Phân bố loại đất & Thổ nhưỡng \\
\hline
\end{tabular}


quả thống kê cho thấy, độ chính xác bản đồ của sản phẩm đối với nhóm đất nông nghiệp và đất mặt nước là khá cao, trên $90 \%$; nhóm đất cây ăn quả và đất dân cư tỉ lệ dự báo chính xác khoảng trên $85 \%$; nhóm đất rừng và cây công nghiệp ở mức chấp nhận được, khoảng 82\%;

Nhìn chung, độ chính xác chung của bản đồ dự báo đến năm 2015 đạt $89 \%$ và hệ số Kappa khoảng 0.88 , kết quả này phản ánh độ tin cậy của mô hình LCM và cho phép tiến hành xây dựng kịch bản sử dụng đất đến năm 2030.

Trong pha xây dựng kịch bản sử dụng đất, các thông số của mô hình chuyển đổi phụ và các biến giải thích được giữ nguyên như trong pha hiệu chỉnh mô hình. Tuy nhiên, bản đồ phân bố nhiệt độ và lượng mưa trung bình năm được xây dựng dựa trên số liệu dự báo biến đổi khí hậu đối với Việt Nam do cục Khí tượng thủy văn và Biến đổi khí hậu công bố hàng năm và dữ liệu giao thông được sử dụng là bản đồ quy hoạch mạng lưới giao thông đến năm 2025. Theo báo cáo trên, đến năm 2030, Việt Nam sẽ chịu những ảnh hưởng của biến đổi khí hậu toàn cầu, trong đó nhiệt độ sẽ tăng khoảng $1^{\circ} \mathrm{C}$ và lượng mưa có thể giảm khoảng $10 \%$. Trên cơ sở dữ liệu lượng mưa và nhiệt độ trung bình năm đã sử dụng trong pha hiệu chỉnh mô hình kết hợp với bản đồ dự báo lượng mưa và nhiệt độ đến năm 2050 toàn quốc, xây dựng kịch bản biến đổi khí hậu riêng cho tỉnh Bình Dương đến năm 2030 và đưa vào mô hình như một biến giải thích đại diện cho yếu tố biến đổi khí hậu ảnh hưởng đến biến động sử dụng đất. Ma trận khả năng chuyển đổi sử dụng đất đến năm 2030 được thiết lập thông qua phân tích chuỗi Markov, nó thể hiện định lượng khả năng chuyển đổi sử dụng đất của từng lớp đối tượng sử dụng đất đến năm 2030. Trong ma trận này, các hàng tương ứng với các lớp sử dụng đất năm 2015 và các cột tương ứng với các đối tượng sử dụng đất được dự báo đến năm 2030. Các giá trị nằm trên đường chéo chính của ma trận thể hiện mức độ biến động của một đối tượng sử dụng sử dụng đất sang các đối tượng khác trong giai đoạn 2015-2030. Trên cơ sở ma trận chuyển đổi tiềm năng đã thiết lập, tiến hành xây dựng bản đồ sử dụng đất tỉnh Bình Dương đến năm 2030 (hình 4).

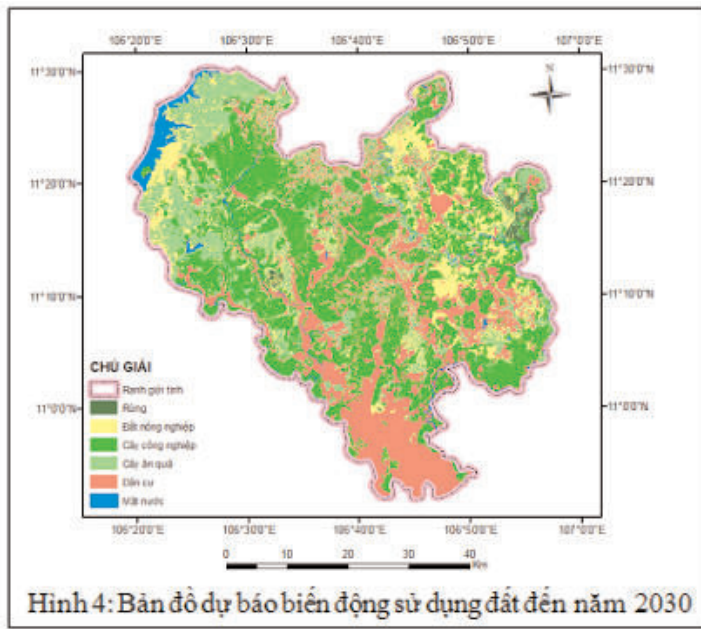

\section{Kết luận}

Sử dụng dữ liệu viễn thám kết hợp với hệ thống thông tin địa lý (GIS) là công cụ hữu ích cho phép thành lập các bản đồ dự báo biến động sử dụng đất các giai đoạn ngắn hạn, trung hạn và dài hạn dựa trên những phân tích biến động lịch sử về sử dụng đất và những yếu tố có ảnh hưởng quan trọng đến quá trình chuyển đổi sử dụng đất thông qua mô hình mô phỏng biến động sử dụng đất LCM (Land Change Modeler). Việc tích hợp đồng thời các yếu tố tự nhiên và các yếu tố do con người gây ra, nhằm phân tích và dự báo xu thế biến động sử dụng đất dựa trên nguyên lý của chuỗi Markov, sử dụng mạng thần kinh đa lớp (Multi-Layer Perceptron) là một cách tiếp cận khoa học. Bản đồ kết quả đạt độ chính xác cao (trên $89 \%$ ) có thể đảm bảo độ tin cậy dự đoán những thay đổi sử dụng đất trong những năm tiếp theo và có thể áp dụng với nhiều khu vực trên toàn quốc. $O$ 


\section{Tài liệu tham khảo}

[1]. Eastman J.R.; Van Fossen M.E., Solarzano, L.A. (2006), Transition Potential Modeling for Land Cover Changeln GIS, Analysis, Spatial, Modeling; Maguire, D.J., Goodchild, M.F., Batty, M., Eds.; ESRI Press: Redlands, CA, USA, 386p.

[2]. Eastman J. Ronald, (2009)IDRISI Taiga: Guide to GIS and Image processing,ClackLab-ClackUniversity. Manual version $16.02,342 p$

[3]. Keith T. Weber, (2012), Forecasting Rangeland Condition in Southeastern Idaho using GIS, Idaho State University GIS Training and ResearchCenter, 921 S. 8th Ave., Stop 8104, Pocatello, Idaho832098104.

[4]. Kumar S., Kumari P., BhaskarU., (2016), Application of Markov Chain \& Cellular Automata based model for prediction of Urban transitions, International Conference on Electrical, Electronics, and Optimization Techniques (ICEEOT).

[5]. Megahed Y., Cabral P., Silva J. and Caetano M., (2015), Land Cover Mapping Analysis and Urban Growth Modelling Using Remote Sensing Techniques in Greater Cairo Region-Egypt, ISPRS Int. J. Geo-Inf. 2015, 4, 1750-1769; doi:10.3390/ijgi4031750.

[6]. Mishra V. N., Rai P. K., Mohan K., (2014), Prediction of land use changes based on land change modeler (LCM) using remote sensing: A case study of Muzaffarpur (Bihar), India, J. Geogr. Inst. Cvijic. 64(1) (111-127), DOI: 10.2298/IJGI1401111M.

[7]. Nedjai R., Nghiem V. T., Do T. P. T., Nasredine M. N., (2016), The impact of land-use and climate change in the centre region of France on the physico-chemical status of aquatic systems, Int. J. Spatial, Temporal and Multimedia Information Systems, Vol. 1, No. 1, 2016.

[8]. Ngân hàng Thế giới và Bộ Kế hoạch và Đầu tư, Việt Nam 2035; doi: 10.1596/978-1-4648-0824-1.

[9]. Nghiem V. T., Nedjai R., Le V. A. and Charleux L. (2013),Application of GIS and remote sensing for predicting land-use change in the French Jura Mountains with the LCM model: the impact of variables on the disturbance mode', Proceeding of the 34th Asian Conference on Remote Sensing, Bali, Indonesia, pp.2588-2595, ISBN: 978602-9439-33-5, (SC04-95 à SC04-102).

[10]. Veldkamp A., Lambinb E.F., (2001), Predicting land-use change, Agriculture, Ecosystems and Environment 85, 1-6.O

\section{Summary}

Mapping forecast land-use change 2030 in Binh Duong province using land changer modeler (LCM) combined with Landsat data

\section{Do Thi Phuong Thao, Bui Ngoc Quy, Nghiem Thị Huyen}

\section{Hanoi University of Minning and Geology}

\section{Mai Van Sy, Hai Phong Design Consultant Investment Joint Stock Company}

The purpose of this study is to establish the forecast map of land use changes the medium term and long term in Binh Duong province with land use land cover by using Land Change Modeler (LCM) and Landsat data. Analytical results forecast map in 2030 showed some type of land use will change significantly can cause serious threats to the urban environment and affect the sustainable development of the area area. $O$ 